\title{
Hemodynamic Responses of Chronically Instrumented Piglets to Bolus Injections of Group B Streptococci
}

\author{
JOSEPH B. PHILIPS III, RAYMOND K. LYRENE, GUILLERMO GODOY, \\ GWENDOLYN GRAYBAR, ELAINE BAREFIELD, J. E. P. SAMS, AND BARRY M. GRAY \\ Perinatal Physiology Research Laboratory, Departments of Pediatrics and Anesthesiology [G. Graybar], \\ University of Alabama at Birmingham, Birmingham, Alabama 35294
}

\begin{abstract}
Group B $\beta$-hemolytic Streptotocci cause pulmonary hypertension when injected into animals and may precipitate the persistent pulmonary hypertension syndrome in infected human neonates. We used chronically instrumented piglets to study the effects of repeated injections of heat-killed group B Streptococcus (GBS) type III. Daily exposure to GBS was associated with a 2 -fold or greater potentiation of pulmonary and systemic hypertensive responses after 1 wk. Throughout experimentation, pulmonary pressure changes were more marked than systemic changes. After establishing a dose-response relationship, we chose a control dose that produced intermediate hypertensive responses. We then evaluated the effects of antibody and various drugs on the hypertensive responses. Preincubation of organisms with rabbit antiserum containing type-specific antibody enhanced the responses. Beta endorphin blockade with naloxone had little or no effect; leukotriene synthesis inhibition also did not affect responses. Both indomethacin, a cyclooxygenase inhibitor, and dazmegrel, a specific thromboxane synthesis inhibitor, blocked the hypertensive responses to GBS. It appears that repeated doses of GBS potentiate the hypertensive responses, a process that we hypothesize may be mediated by development of type-specific antibody as type-specific antibody levels rose during potentiation. It is likely that thromboxane $A_{2}$ is the effector of the pulmonary and systemic hypertensive responses to GBS injection, because thromboxane inhibition by dazmegrel was as effective as indomethacin in blocking these effects. Thromboxane synthesis blockade may prove useful in management of hemodynamic disturbances accompanying severe bacterial infections in humans. (Pediatr Res 23: 81-85, 1988)
\end{abstract}

\section{Abbreviations}

BSA, bovine serum albumin

CFU, colony forming units

GBS, group B Streptococcus

PBS, phosphate-buffered saline

$\overline{\mathbf{P}}$ pa, mean pulmonary artery pressure

Pas, systemic artery pressure

$\overline{\mathbf{P}}$ la, mean left atrial pressure

$\overline{\mathbf{P}} \mathrm{cv}$, mean central venous pressure

Qpa, pulmonary artery flow

PVR, pulmonary vascular resistance

SVR, systemic vascular resistance

Received November 24, 1986; accepted September 18, 1987.

Correspondence and reprints Joseph B. Philips, III, M.D., Box 162, The Children's Hospital, 1600 7th Avenue South, Birmingham, AL 35233.

Supported in part by grants from The American Heart Association/Alabama Affiliate and NICHD Program Project S POI HD17812.
ELISA, enzyme-linked immunosorbent assay ABTS, 2,2'-azinobis(3-ethylbenz-thiazoline sulfonic acid) ANOVA, analysis of variance

It is well known that gram-negative bacterial sepsis and endotoxemia are associated with profound hemodynamic disturbances. More recently, gram-positive bacteria, especially group B Streptococcus, have also been shown to be associated with circulatory disturbances in infected noenates. Clinically these infants may manifest the persistent pulmonary hypertension syndrome wherein continued right-to-left extrapulmonary shunting occurs because of abnormally elevated pulmonary artery pressure and resistance $(1,2)$. Infusions of GBS into experimental animals have been shown to cause marked hemodynamic alterations in the pulmonary and systemic circulations (3-5).

We developed a chronically instrumented piglet preparation that permitted repeated injections of heat-killed GBS in conscious animals. We first evaluated the effects of repeated injections of the same organism to test the hypothesis that repeated exposure to GBS was associated with changes in the hypertensive responses. We then attempted to modify the hypertensive responses with immunologic and pharmacologic probes in order to gain insight into the mechanisms underlying these GBSinduced responses.

\section{MATERIALS AND METHODS}

Piglets. Twelve juvenile female piglets weighing $6.8 \pm 2.1 \mathrm{~kg}$ (mean $\pm \mathrm{SD}$, range $4.4-11.8 \mathrm{~kg}$ ) were anesthetized and mechanically ventilated using standard anesthesia equipment. Heart rate and colonic temperature were monitored; a heating pad was used to minimize intraoperative hypothermia. A left thoracotomy was performed with removal of the third rib. The pericardium was incised, and a precalibrated $10-\mathrm{mm}$ electromagnetic flow transducer (Biotronix Laboratories, Kensington, MD) was placed around the main pulmonary artery. A 5 French polyurethane catheter (courtesy Ray Bodicky, Sherwood Medical, St Louis, MO) was inserted into the pulmonary artery through a pursestring suture placed between the pulmonary valve and the flow transducer. These catheters do not interfere with the flowmeter readings (6). Another 5 French catheter was inserted into the left atrium. Catheters were checked for blood return and flushed with $0.85 \%$ saline containing $10 \mathrm{U} / \mathrm{ml}$ heparin. The parietal pleura was closed and the flow probe and catheters passed through a subcutaneous tunnel to a left flank incision. The chest wound was then closed.

Next, 5 French catheters were inserted into the left femoral 
artery and vein via a left groin incision and were tunneled to the same flank incision. Both the groin and flank incisions were closed, and all devices were stored inside a pouch secured to the left flank. A "sweater" of tubular elastic, with holes for the forelimbs and ending at the hind limbs, was then placed to help protect the pouch. The piglets were maintained in cages with elevated floors to prevent soiling of sweaters and incisions. Catheters were flushed daily (except Sundays) with heparinized $0.85 \%$ saline and $100 \mathrm{mg} / \mathrm{kg} /$ day oxytetracycline was given intravenously for the first week. Animals instrumented in this fashion have been maintained for up to $6 \mathrm{wk}$, during which time they grow rapidly. Studies were not performed on animals that appeared ill and at least 4 days were allowed between surgery and the first experiment.

Organisms. Cultures of GBS type III (strain M732) were grown to late log phase in Todd-Hewitt broth, heat-killed at $80^{\circ} \mathrm{C}$ for $15 \mathrm{~min}$, and harvested by centrifugation. Bacteria were then washed twice, and suspended in PBS $(0.05 \mathrm{M}$ phosphate, $0.1 \mathrm{M}$ $\mathrm{NaCl}, \mathrm{PH} 7.4$ ) to an optical density of 0.6 at $590 \mathrm{~nm}$ (about $1 \times$ $10^{9} \mathrm{CFU}$ ). Aliquots were stored at $-60^{\circ} \mathrm{C}$ until use. Confirmation of GBS killing was acomplished by culturing a sample of each batch of organisms and only those batches with no growth were used in these studies.

Experiments. For each experiment, the conscious piglet was placed in a sling device that supported and secured the animal but kept the extremities elevated. Catheters were flushed and connected to precalibrated Statham P23-1D transducers, which in turn were connected to physiologic recorders ( 2 Gould-Brush 2400 series). The blood flowmeter (Biotronix Laboratories, Kensington, MD) was also attached and zeroed using the diastolic no-flow component of the phasic flow signal. We recorded phasic systemic arterial pressure plus electronically derived mean pulmonary, left atrial and central venous pressures, plus mean pulmonary artery flow. Each study consisted of the rapid $(5 \mathrm{~s})$ intravenous injection of the desired dose of organisms. When more than one injection was made, tracings were allowed to stabilize and remain stable for at least $5 \mathrm{~min}$ prior to the next infusion.

posure to the same organism, we injected $1 \times 10^{8} \mathrm{CFU} \mathrm{GBS} / \mathrm{kg}$ ( $0.1 \mathrm{ml}$ of GBS suspension) daily (except Saturday and Sunday) into 12 animals for 10 calendar days. Studies always began on a Tuesday and ended on a Thursday.

Dose-response curve. Once the hemodynamic response to $1 \times$ $10^{8} \mathrm{CFU} \mathrm{GBS} / \mathrm{kg}$ had stabilized (about 10 days) we constructed a dose-response relationship in six animals by giving doses ranging from $5 \times 10^{6}$ to $2.5 \times 10^{8} \mathrm{CFU} \mathrm{GBS} / \mathrm{kg}$. Two doses of one $\log$ difference were usually given each day. The order of doses was randomized.

Immunologic and Pharmacologic Modification. After establishing a dose-response curve, we selected a dose $\left(5 \times 10^{7} \mathrm{CFU}\right.$ $\mathrm{GBS} / \mathrm{kg}$ ) that produced an intermediate pulmonary hypertensive response. Each of the following studies was performed in previously potentiated animals. Ten animals received the control dose. Six animals received similar injections of GBS which had been preincubated for $5 \mathrm{~min}$ with $0.2 \mathrm{ml}$ of rabbit antiserum containing $4.9 \mathrm{mg} / \mathrm{ml}$ of type-specific antibody as determined by quantitative precipitation. Four of the above six animals were given $0.2 \mathrm{ml}$ of the rabbit antiserum without GBS. Six piglets were given $0.1 \mathrm{mg} / \mathrm{kg}$ of the $\beta$-endorphin blocker, naloxone, followed in $10 \mathrm{~min}$ by the organisms. Five piglets were pretreated with $0.1 \mathrm{mg} / \mathrm{kg}$ of a putative leukotriene synthesis inhibitor, A $540 \mathrm{C}$ (courtesy of Dr. Walker Long, Burroughs Wellcome Company, Research Triangle Park, NC), followed by the organisms 10 min later. Six animals were similarly pretreated with $1 \mathrm{mg} / \mathrm{kg}$ of the thromboxane synthase inhibitor, dazmegrel (courtesy of Dr. Pedro Urquilla, Pfizer Central Research, Groton, CT) and four piglets were given $2 \mathrm{mg} / \mathrm{kg}$ of the cyclooxygenase inhibitor, indomethacin (courtesy of Merck, Sharp and Dohme, West Point, PA). Dazmegrel, indomethacin, and A 540C were each prepared fresh on the day of use according to the manufacturers' recommendations.
To ascertain that the suspending medium was hemodynamically inert, six animals were also given injections of $0.1 \mathrm{ml} /$ $\mathrm{kg}$ of PBS which had been centrifuged and passed through a 0.45 $\mu \mathrm{m}$ microporous filter to remove GBS. This was done to rule out possible leakage of a "toxin" from the dead bacteria.

Type-specific antibody measurements. The antibody response of piglets was measured by an ELISA method similar to that previously described (7). The GBS type III antigen was prepared from strain M732 by mutanolysin extraction essentially as described by DeCuenink et al. (8). Antigen was coupled to polylysine (9) and dispensed in $250-\mu l$ volumes into plastic microtiter wells, allowed to adsorb overnight, rinsed with water, and then blocked with $0.1 \%$ BSA for $1 \mathrm{~h}$ prior to adding piglet serum. Piglet sera were diluted $1 / 1000$ to $1 / 4000$ in PBS containing $0.1 \%$ BSA and $0.05 \%$ Brij-35 (Aldrich Chemical Co., Atlanta, GA) and diluted sera were added to wells in $250-\mu$ l volumes and incubated for $1.5 \mathrm{~h}$ at room temperature. After washing out unbound antibodies, a peroxidase-conjugated rabbit antiporcine antibody (heavy and light chain-specific, Cooper Biomedical, diluted in PBS + BSA + Brij) was added and incubated for $1 \mathrm{~h}$. After washing out excess conjugate, the substrate ABTS (Sigma Chemical Co., St. Louis, MO) diluted $1 \mathrm{mg} / \mathrm{ml}$ in citrate buffer, pH 7.0 , with $0.03 \% \mathrm{H}_{2} \mathrm{O}_{2}$ was added and the resulting color change recorded at $414 \mathrm{~nm}$ in a multichannel photometer. The amount of antibody in each sample was quantitated against serial dilutions of standard serum $(0.2-2.0 \mu \mathrm{l} /$ well) from a single piglet immunized with GBS type III. The antibody content of this serum was $60.0 \mu \mathrm{g} / \mathrm{ml}$; this was measured in the ELISA against a standard curve consisting of ${ }^{125}$ I-labeled antibody prepared from the $50 \%$ ammonium sulfate precipitate of the same serum. The amount of specific antibody in the ${ }^{125}$ I-labeled fraction was determined in serial dilutions incubated in GBS type III antigencoated wells for $6 \mathrm{~h}$ (essentially maximal binding); the amount of antibody bound at each dilution was determined from ${ }^{125} \mathrm{I}$ counts in each well and the known specific activity per $g{ }^{125} \mathrm{I}$ labeled protein; the antibody concentration was then calculated from 5 points at which the amount of antibody added approached $100 \%$ binding.

Statistical analysis. For each experiment, preinfusion baseline values were recorded and mean Pas was calculated. Maximal $\bar{P}$ pa after GBS was then recorded along with the simultaneous

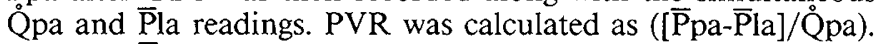
Maximal $\bar{P}$ as values were also recorded. The change $(\Delta)$ in each value from baseline was then calculated. The change values were tabulated as matrices and analyzed by one-way or two-way analysis of variance. For the time-related and dose-related data, the appropriate F statistic was calculated. Dunnett's test was used to test the effects of the various modifying treatments against the control response and to simultaneously control for multiple comparisons (10). For display of data, the mean value \pm 1 SD was graphed in order to show the variability of data within each group.

\section{RESULTS}

Preinfusion baseline values were stable through the period of study in each animal and exhibited no upward or downward trends over time. Mean ( \pm SD) values for each measured variable at baseline were: $\overline{\mathrm{P}} \mathrm{s}=91 \pm 6 \mathrm{~mm} \mathrm{Hg} ; \overline{\mathrm{P}} \mathrm{pa}=18 \pm 2 \mathrm{~mm} \mathrm{Hg}$ : $\overline{\mathrm{Pla}}=8 \pm 1 \mathrm{~mm} \mathrm{Hg} ; \overline{\mathrm{P}} \mathrm{cv}=9 \pm 1 \mathrm{~mm} \mathrm{Hg}$; and Q̊pa $=590 \pm$ $190 \mathrm{ml} / \mathrm{min}$.

Figures 1 and 2 show that repeated infusions of $1 \times 10^{8} \mathrm{CFU}$ $\mathrm{GBS} / \mathrm{kg}$ were associated with a potentiation of the pulmonary and systemic hypertensive responses after about 7 days. After this potentiation matured, the response in each piglet was quite stable for the remainder of experimentation. Injection of the same dose of GBS $19 \pm 4$ days after the first dose gave a mean $\bar{P}$ pa increase of $22.2 \pm 3.3 \mathrm{~mm} \mathrm{Hg}$, compared to $20.6 \pm 3.0 \mathrm{~mm}$ $\mathrm{Hg}$ for the average value on days 8-10 in the same animals ( $p=$

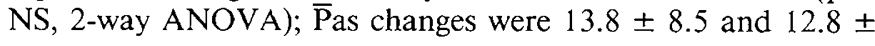




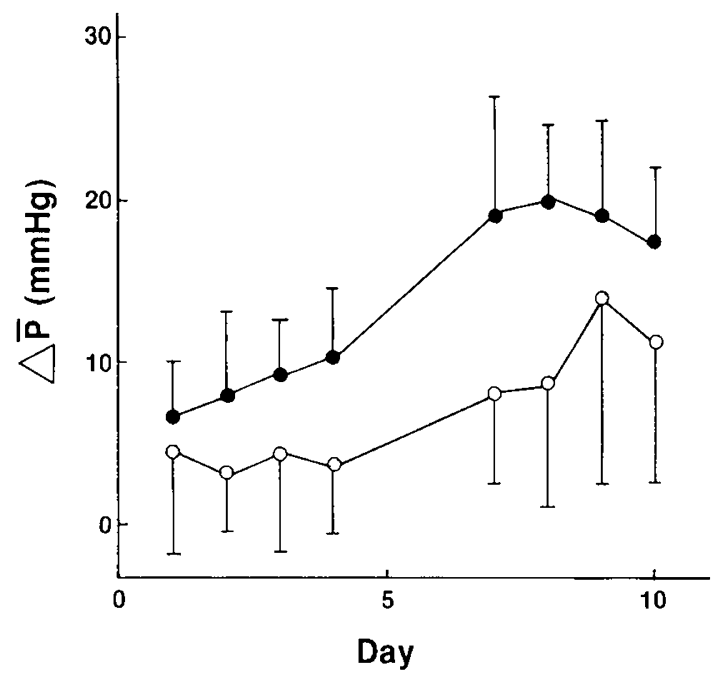

Fig. 1. Time-related potentiation of $\Delta \overline{\mathrm{P} p a}(\bullet)$ and $\Delta \overline{\mathrm{P}}$ as $(\mathrm{O})$ responses on each study day to repeated doses of $1 \times 10^{8}$ heat-killed CFU GBS/ kg. Bars represent $1 \mathrm{SD} . n=12$ for $\Delta \overline{\mathrm{P}} \mathrm{pa}, p<0.0001 ; n=7$ for $\Delta \overline{\mathrm{P}} \mathrm{as}, p$ $=0.042$.
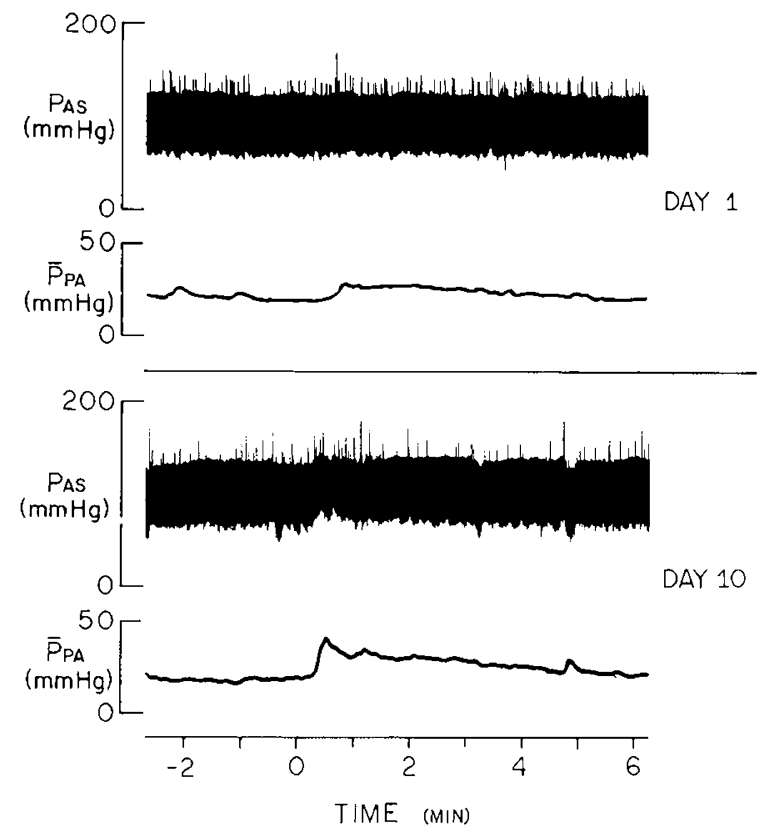

Fig. 2. Actual tracings showing responses to bolus injections of $1 \times$ $10^{8} \mathrm{CFU} \mathrm{GBS} / \mathrm{kg}$ on days 1 and 10 in the same animal. Note marked alteration in Ppa response and the smaller effect on Pas. Note also that duration of $\bar{P}$ pa response is much longer than that for Pas.

$7.8 \mathrm{~mm} \mathrm{Hg}$ for the same five animals on the same dates ( $p=$ NS). Piglets were referred to as "potentiated" after undergoing the 10-day course of repeated injections. Changes in Q̊pa, $\bar{P} l a$, and $\overline{\mathrm{P}} \mathrm{cv}$ (not shown) were small and variable in comparison to the $\bar{P}$ pa and $\bar{P}$ as responses. Because Q pa and $\bar{P}$ la changes were small, changes in calculated PVR were similar to those for $\bar{P}$ pa. We also noted that the shape of the tracing for the pulmonary pressure response often changed in association with potentiation (Fig. 2). Initially, the $\bar{P}$ pa trace drifted upward, peaked slowly, and then gradually drifted downward. After potentiation, $\bar{P}$ pa increased more rapidly, peaked earlier, and then rapidly decayed to the gradual decline phase. Changes in $\bar{P}$ pa were larger than those for $\overline{\mathrm{P}}$ as throughout experimentation and the $\overline{\mathrm{P}}$ pa elevations lasted much longer (3-5 min) than did those for $\widetilde{P} a s(\leq 1 \mathrm{~min})$.

Once piglets became potentiated, a dose-response curve was constructed as shown in Figure 3. Doses less than $5 \times 10^{6} \mathrm{CFU}$ $\mathrm{GBS} / \mathrm{kg}$ had little or no effect. Increasing doses then produced increasing hypertensive responses up to about $1 \times 10^{8} \mathrm{CFU}$ GBS $/ \mathrm{kg}$. Again, the dominant effect was on the $\bar{P}$ pa variable, with lesser changes seen for $\bar{P}$ as. No consistent effects were noted for $\overline{\mathrm{P}} \mathrm{la}, \overline{\mathrm{P}} \mathrm{cv}$ or Qpa. Thus, changes in PVR again paralleled those for $\bar{P}$ pa.

The results of immunologic and pharmacologic treatments are displayed in Figure 4. Control doses of $5 \times 10^{7} \mathrm{CFU}$ GBS $/ \mathrm{kg}$ produced a $\Delta \overline{\mathrm{P}}$ pa of $16.4 \pm 5.7$ and a $\Delta \overline{\mathrm{P}}$ as of $5.1 \pm 3.6 \mathrm{~mm} \mathrm{Hg}$ in potentiated piglets. Injection of organisms preincubated for 5 min with rabbit antiserum resulted in significantly higher pulmonary and systemic responses. Injection of an equal volume of antiserum without GBS into four animals (data not shown) had no effect on $\Delta \overline{\mathrm{P}} \mathrm{pa}(-0.2 \pm 1.7 \mathrm{~mm} \mathrm{Hg}, p=\mathrm{NS})$ but had a small effect on $\Delta \overline{\mathrm{P}}$ as $(4.0 \pm 2.2, p=0.04)$. Neither the endorphin blocker, naloxone, nor the putative leukotriene synthesis inhibitor, A $540 \mathrm{C}$, altered the pulmonary response to GBS injection. The systemic response was higher after A 540C than during control. The thromboxane synthesis inhibitor, dazmegrel, blocked the pulmonary and systemic hypertensive effects of GBS, as did the cyclooxygenase inhibitor, indomethacin. PBS from which organisms had been removed produced no discernable hemodynamic effect on either variable.

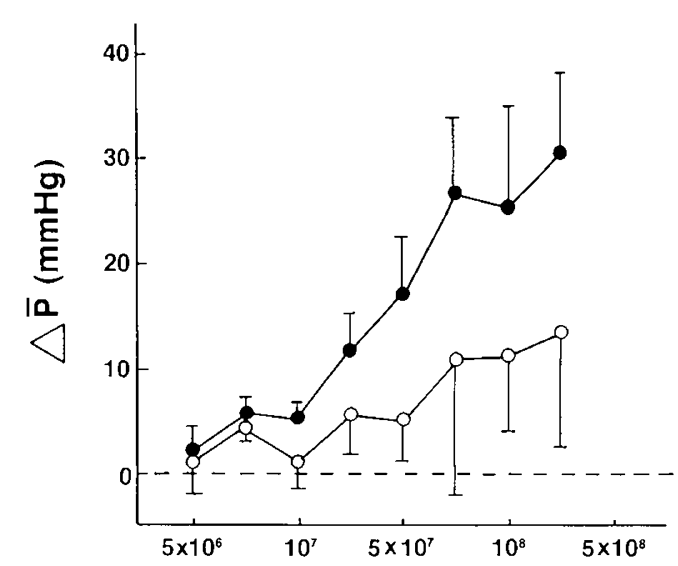

Fig. 3. Dose-response relationship for $\Delta \overline{\mathrm{P}} \mathrm{pa}(\bullet)$ and $\Delta \overline{\mathrm{P}}$ as $(O)$ in potentiated animals. Bars represent 1 SD. $n=6, p<0.0001$ for $\Delta \overline{\mathrm{P} p a} ; p$ $=0.017$ for $\Delta \overline{\mathrm{P}}$ as.

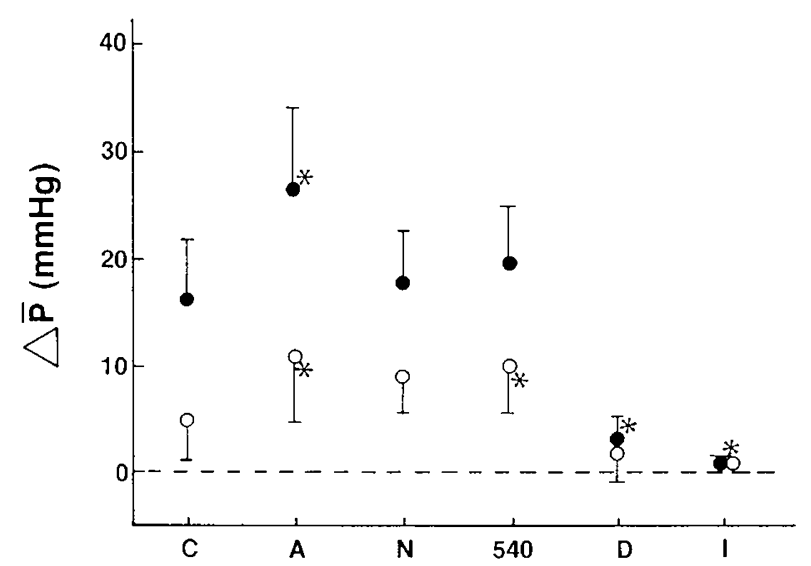

Fig. 4. The effects of immunologic and pharmacologic modification of the hypertensive change $(\Delta)$ in $\overline{\mathrm{P}} \mathrm{pa}(\bullet)$ and $\overline{\mathrm{P}}$ as $(O)$ caused by injection of $5 \times 10^{7} \mathrm{CFU} \mathrm{GBS} / \mathrm{kg}(C)$, by injection of antibody pretreated GBS $(A)$, by pretreatment of piglets with naloxone $(N)$, A 540C (540), dazmegrel $(D)$, and indomethacin $(I) .{ }^{*} p<0.05$ when compared to control using Dunnett's test. 
Serum samples from nine piglets were assayed for GBS type III-specific antibodies. Serologic responses increased at least 4 fold in eight of nine piglets by day 14 of the study and in all by day 21 . The magnitude of antibody response varied considerably, from $<1.0 \mu \mathrm{g} / \mathrm{ml}$ before potentiation to $6.0-228 \mu \mathrm{g} / \mathrm{ml}$ after potentiation (median $36 \mu \mathrm{g} / \mathrm{ml}$ ).

\section{DISCUSSION}

We have developed a chronically instrumented piglet preparation that allows us to study repeatedly the hemodynamic effects of heat-killed bacteria. To our knowledge, these are the first studies of the effects of whole GBS in chronically instrumented, conscious juvenile piglets. The responses of our animals to GBS are qualitatively similar to those seen in acutely instrumented anesthetized animals under somewhat different conditions of GBS infusion.

We have observed a new finding-the potentiation of the pulmonary hypertensive response after repeated daily doses of the same organism. Once "potentiated," piglets retained their heightened responsiveness for the remainder of experimentation. The mechanisms underlying this potentiation of response are presently unclear. One possibility is that the piglets developed antibodies to the GBS during potentiation and that these antibodies, when combined with GBS, triggered the elevated responses seen after potentiation. This is suggested by the observation that organisms preincubated with type-specific rabbit antiserum produced even higher responses in potentiated animals. It was also found that eight of nine piglets made serologic responses to the GBS type III-specific polysaccharide by day 14 of the study. However, the magnitude of response varied considerably from one piglet to another, and it is further possible that antibodies to surface components other than the type-specific capsular material are important in the potentiation.

While there clearly are differences between the piglet model and the situation in sick or compromised humans, several possible implications of these results should be considered. Individuals do not ordinarily become infected with organisms against which they have antibody. However, some patients may become infected despite the presence of antibody, and debilitated or immunosuppressed patients may become infected with organisms to which they are immune. Similar problems could develop with use of passive immunization in infected patients. In the above situations, presence of large amounts of antibody could exacerbate cardiovascular symptoms. It is possible that administration of exogenous type-specific antibody-containing preparations could precipitate or worsen preexisting pulmonary hypertension in septic newborns with circulating bacteria or free antigen. Further animal studies should be performed before antibody-containing preparations receive widespread clinical use. These untoward effects of antibody may not be advantageous to the host, but may be the price paid for the desired abilities to opsonize, rapidly remove, and destroy circulating organisms.

Our studies, like others performed in acutely instrumented animals, have clearly shown that arachidonic acid pathway products are the effectors of GBS-induced pulmonary hypertension in the piglet model. Cyclooxygenase blockade by indomethacin prevents GBS-induced pulmonary hypertension, thereby implicating thromboxane $A_{2}$ (the biologically active thromboxane) or a prostaglandin as the active agent. The effectiveness of dazmegrel, a selective thromboxane synthase inhibitor, strongly suggests that thromboxane $A_{2}$ is the active agent, because dazmegrel blocked the hypertensive responses as efficiently as indomethacin. Elevated thromboxane levels have been reported in studies of GBS-induced pulmonary hypertension $(4,7)$, also suggesting that thromboxane $\mathrm{A}_{2}$ causes the observed pulmonary hypertension. The study of Truog et al. (11) showed that dazmegrel pretreatment blocks GBS-induced pulmonary hypertension and thromboxane release in acutely instrumented piglets.
The source of thromboxane is presently unknown. Platelets can produce large quantities of thromboxane $A_{2}$ and may be involved in the above described responses. Shoemaker et al. (12) have shown that exteriorized, perfused rabbit lungs developed pulmonary artery hypertension when both platelets and Staphylococcus aureus were included in the perfusate; bacteria alone did not induce pulmonary hypertension. Thromboxane levels were very high in the lungs perfused with platelets plus bacteria, but were low in those perfused with bacteria alone. Additional thromboxane sources might include other formed elements in blood (polymorphonuclear leukocytes, etc.), vascular endothelium, or others. The mechanisms whereby antigen-antibody complexes may augment thromboxane release and potentiate GBSinduced pulmonary hypertension are presently unknown and could involve any of a number of mediators including complement, platelet-activating factor, or other intermediary compounds.

Neither the leukotrienes nor the $\beta$-endorphins appear to be involved in GBS-induced pulmonary hypertension. Blockade of these two families of agents did not affect the response to a subsequent challenge with GBS. These are the first studies, to our knowledge, that evaluate the effect of $\beta$-endorphin blockade in GBS-induced pulmonary hypertension. However, pulmonary hypertension is only one of several circulatory derangements observed after injection of organisms into animals. Prolonged bacterial infusions ultimately lead to circulatory shock and collapse $(3,4)$. In addition, pulmonary lymph flow and pulmonary vascular permeability to protein increase following GBS infusion, which may lead to pulmonary edema formation $(13,14)$. Leukotrienes and/or endorphins, as well as other compounds, may be involved in these later phases of the host response to bacteremia.

A shortcoming in this study is that we did not directly confirm blockade of the various pathways investigated. Of particular interest is the putative leukotriene synthesis inhibitor, A 540C, which is stated by the manufacturer to inhibit leukotriene synthesis in the dose used (Long W, personal communication). Tenfold higher doses also inhibit cyclooxygenase. The observation that A 540C did not block GBS-induced pulmonary hypertension documents that cyclooxygenase was intact at the doses used. However, whether A 540C blocked the 5-lipoxygenase pathway is not certain in our study. Goldberg et al. (15) used the leukotriene receptor antagonist FPL-5723 1 and showed partial reversal of GBS-induced pulmonary hypertension. Others have had difficulty in replicating these results. In contrast, the reductions in GBS-induced pulmonary hypertension by indomethacin and dazmegrel indicate their effectiveness at the doses used. Even here, however, we cannot say with absolute certainty that thromboxane synthesis was inhibited by these drugs as we did not measure circulating eicosanoids. It is possible, but not likely, that indomethacin and dazmegrel blocked the GBS response by mechanisms other than cyclooxygenase and thromboxane synthase inhibition. We consider this unlikely given the reasonably good understanding of the mechanisms of action of these compounds.

Infusions of GBS result in decreased $\mathrm{PaO}_{2}$ (11). We did not assess the effects of bolus GBS on arterial blood gases during this study. Thus, if rapid decreases in $\mathrm{PaO}_{2}$ occurred with GBS injection, hypoxia might have accounted for part of the observed pulmonary hypertensive changes. Further studies are necessary to determine what contribution, if any, hypoxemia makes to the total pulmonary hypertensive response to GBS, both acutely as in the present study, and more long term as in continuous GBS infusion studies.

Our studies clearly show that the hemodynamically active component(s) of GBS are firmly attached to and exposed on the surface of the bacteria. Injections of suspending medium from which organisms had been removed by centrifugation and filtration on the day of experimentation were devoid of hemodynamic effects. At present, the identity of the hemodynamically active 
surface component(s) is unknown, although we have presented preliminary evidence that the type-specific antigen is active after potentiation (16). We have observed severe acute pulmonary hypertension in potentiated piglets given as little as $200 \mu \mathrm{g}$ of purified GBS type III-specific antigen, whereas nonpotentiated piglets show little or no response. Our results differ somewhat from those of Hellerqvist et al. (17) who identified a hemodynamically active polysaccharide in the media in which GBS type III had been grown. Infusions of washed, heat-killed bacteria resuspended in PBS were not associated with hemodynamic activity in their study. We are uncertain as to why such a striking difference exists between our study and that of Hellerqvist et al. (17).

Our present studies have been confined primarily to effects of GBS type III. We have presented preliminary evidence that other gram-positive bacteria, including pneumococci and staphylococci, also produce pulmonary hypertension, and that their effects are also blocked by pretreatment with indomethacin (18). It is likely that a large number of microbial species evoke similar responses. Continued infusion of living GBS organisms into animals has been shown to lead to cardiovascular collapse $(3,4)$. Similar hemodynamic derangements probably occur in infected humans and much of the morbidity and mortality of grampositive septicemia may be due to these phenomena.

In summary, we have established an animal model that allows study of the circulatory effects produced by repeated injection of dead bacteria. We have discovered that repeated challenge with the same organism is associated with a potentiation of the pulmonary and systemic hypertensive responses after about 1 wk and have hypothesized that type-specific antibody mediates this potentiation. Dazmegrel, a specific thromboxane synthesis inhibitor, was as effective as indomethacin in blocking the hypertension induced by GBS injection. We have also recently shown that dazmegrel reverses preexisting GBS-induced pulmonary hypertension in acutely instrumented piglets, despite continued infusion of GBS (19). Indomethacin blocks all prostaglandin and thromboxane production, but has powerful and potentially undesirable hemodynamic effects of its own. Dazmegrel, in contrast, was free of hemodynamic side effects in both our conscious and acutely studied animals. The ability to selectively inhibit thromboxane synthesis in septicemic humans may prove beneficial. Newborn humans infected with GBS may develop the persistent pulmonary hypertension syndrome; older individuals infected with gram-positive organisms may also develop hemodynamic derangements. Thromboxane $\mathrm{A}_{2}$ may mediate some of these deleterious effects. It is possible that dazmegrel, or a similar inhibitor of thromboxane synthesis, could be used clinically in treatment of severe bacterial infections.

\section{REFERENCES}

1. Shankaran S, Farooki Z, Desai R $1982 \beta$-Hemolytic streptococcal infection appearing as persistent fetal circulation. Am J Dis Child 136:725-729

2. Hageman JR, Adams MA, Gardner TH 1983 Persistent pulmonary hypertension of the newborn with early onset neonatal infection. Pediatr Res 17:315A

3. Meadow WL, Meus PJ 1984 Hemodynamic consequences of tolazoline in neonatal group B streptococcal bacteremia: an animal model. Pediatr Res 18:960 965

4. Runkle B, Goldberg RN, Streitfeld MM, Clark MM, Buron E, Setzer ES, Bancalari E 1984 Cardiovascular changes in Group B streptococcal sepsis in the piglet: response to indomethacin and relationship to prostacyclin and thromboxane $\mathrm{A}_{2}$. Pediatr Res 18:874-878

5. Huddleston KW, Lyrene RK, Dew A, Gray BW, Philips JB 1986 Influence of prostaglandin $D_{2}$ on hemodynamic effects of Group B Streptococcus in neonatal lambs. Dev Pharmacol Ther 9:260-265

6. Philips JB, Lyrene RK, McDevitt M, Perlis W, Satterwhite C, Cassady G 1983 Prostaglandin $\mathrm{D}_{2}$ inhibits hypoxic pulmonary vasoconstriction in neonatal lambs. J Appl Physiol 54:1585-1589

7. Gray BM, Pritchard DG, Dillon HC, Jr. 1985 Seroepidemiological studies of group B Streptococcus type II. J Infect Dis 151:1073-1080

8. DeCueninck BJ, Shockman GD, Swenson RM 1982 Group B, type III streptococcal cell wall: composition and structural aspects revealed through endo$\mathrm{N}$-acetylnuramidase-catalyzed hydrolysis. Infect Immun 35:57

9. Gray BM 1979 ELISA methodology for polysaccharide antigens: protein coupling of polysaccharides for adsorption to plastic tubes. J Immunol Methods 28:187-192

10. Dunnett CW 1955 A multiple comparison procedure for comparing several treatments with a control. J Am Stat Assoc 50:1096-1121

11. Truog WE, Sorensen GK, Standaert TC, Redding GJ 1986 Effects of the thromboxane synthetase inhibitor, dazmegrel (UK 38, 485) on pulmonary gas exchange and hemodynamics in neonatal sepsis. Pediatr Res 20:481-486

12. Shoemaker SA, Heffner JE, Canham EM, Tate RM, Morris HG, McMurtry IF, Repine JE 1984 Staphylococcus aureus and human platelets cause pulmonary hypertension and thromboxane generation in isolated salineperfused rabbit lungs. Am Rev Respir Dis 129:92-95

13. Rojas J, Palme C, Ogletree ML, Hellerqvist CG, Brigham KL, Stahiman MT 1984 Effects of methylprednisolone on the respone to Group B streptococcal toxin in sheep. Pediatr Res 18:1141-1144

14. Rojas J, Green RS, Hellerqvist CG, Olegard R, Brigham KL, Stahlman MT 1981 Studies on Group B beta-hemolytic streptococcus: II. Effects on pulmonary hemodynamics and vascular permeability in unanesthetized sheep. Pediatr Res 15:899-904

15. Goldberg RN, Suguihara C, Streitfeld MM, Bancalari A, Clark MR, Bancalari E 1986 Effects of a leukotriene antagonist on the early hemodynamic manifestations of group B streptococcal sepsis in piglets. Pediatr Res 20:1004-1008

16. Philips J, Huddleston K, Lyrene R, Godoy G, Prichard D, Graybar G, Sams JEP, Oliver J, Cassady G, Gray B 1986 Role of type-specific antigen in pulmonary hypertensive response to Group B streptococcus in piglets. Pediatr Res 20:401A

17. Hellerqvist CG, Rojas J, Green RS, Sell S, Sundell H, Stahlman MT 1981 Studies on Group B-hemolytic streptococcus. I. Isolation and partial characterization of an extracellar toxin. Pediatr Res 15:892-898

18. Welch KA, Godoy G, Dew A, Gary BM, Lyrene RK, Philips JB 1984 Pulmonary hypertension following bolus infusions of pneumococcus, other gram positive bacteria and zymosan. Circulation 70:II-425

19. Tarpey MN, Graybar GB, Lyrene RK, Godoy G, Oliver J, Gray BM, Philips JB, III 1987 Thromboxane synthesis inhibition reverses group B streptococcus-induced pulmonary hypertension. Crit Care Med 15:644-647 